\title{
Discursos religiosos y seculares en la legitimación de las prácticas religiosas. Las leyes dietéticas en el judaísmo
}

\author{
Damián SETTON
}

\begin{abstract}
resumo $\mathrm{O}$ trabalho analisa como o movimento judeu religioso Chabad Lubavitch constróe o sentido da prática do Kashrut (leis dietéticas), recorrendo a legitimaçóes provenientes do campo da medicina, bem como às matrizes discursivas seculares vinculadas com a memória da tragédia e da sobrevivência do povo judeu. O objetivo é analisar as continuidades entre o religioso e o secular nas estratégias de posicionamento no campo judaico dos movimentos proselitistas. Pois, a fim de legitimar a prática religiosa, o movimento Chabad Lubavitch recorre a significados seculares. Mas pondo em circulação estes significados, ele corre o risco de dar uma grande ênfase aos aspectos seculares das práticas judaicas. E para evitar que isso ocorra, o movimento administra a circulação destes significados.
\end{abstract}

palavras-chave Judaísmo. Secularização. Legitimações. Chabad Lubavitch. Kashrut.

\section{Introducción}

Las prácticas judaicas en la modernidad han pasado por procesos de resignificación donde lo religioso y lo secular se han opuesto e interpenetrado a la vez. El siglo XX marca la hegemonía de las corrientes seculares en el seno del judaísmo. Los sectores guardianes de una concepción halájica ${ }^{1}$ de la vida judía ocupan posiciones marginales en el campo judaico ${ }^{2}$, hasta que a partir de las décadas de 1970 y 1980 se asiste a la revitalización de la ortodo- xia religiosa a través de diversos movimientos religiosos como Aish ha Torá (fuego de la Torá) o Jabad Lubavitch y político- religiosos como el SHAS israelí. No obstante, el discurso que los movimientos ortodoxos ponen en escena es tributario de significados construidos en universos de sentido seculares. Nuestro objetivo es analizar estas continuidades a través de la interpenetración de los significados en torno a una práctica específica: las leyes dietéticas en el judaísmo, las leyes del Kashrut ${ }^{3}$. Pretendemos echar luz sobre la relaciones entre lo religiosos y lo secular en las estrategias de posicionamiento en el campo judaico de grupos religiosos proselitista ${ }^{4}$, mostrando que dichas dimensiones no conforman polaridades antagónicas, sino que la circulación de significados construye tramas más complejas donde lo religioso y lo secular se articulan bajo contornos flexibles y difusos.

\section{Revitalización religiosa en Buenos Aires}

El caso que hemos tomado para el análisis es la "comunidad"5 judía de la ciudad de la ciudad de Buenos Aires. Se trata, a nivel cuantitativo, de la mayor comunidad judía de Latinoamérica. Con más de un siglo de existencia, ha pasado por las diversas etapas que han marcado al mundo judío a nivel mundial, desde el desarrollo de los grupos anarquistas, socialista, 
comunistas y bundistas, todos ellos portadores de proyectos identitarios no religiosos, pasando por la transformación del sionismo en corriente hegemónica hasta llegar al proceso de revitalización religiosa que recorre también los campos judaicos de contextos diferentes como Estados Unidos (Danzger, 1989), Brasil (Gruman, 2002, Topel, 2005), Francia (Podselver, 1992, 2002) e Israel (Aviad, 1983).

En el proceso de revitalización religiosa en Argentina, quizás el movimiento más activo haya sido Jabad Lubavitch ${ }^{6}$. El mismo se inicia en este país en la década del cincuenta, con la llegada desde Estados Unidos de Dovber Baumgarten, emisario del rebe $e^{7}$ Pero será en la década del ochenta que, bajo la dirección del rabino Tzvi Grunblatt, y en el contexto de democratización que pone fin a un largo período de alternancia entre gobiernos constitucionales y dictaduras militares portadoras de discursos afines al catolicismo integral, que la presencia de Jabad Lubavitch se hace cada vez más evidente. En efecto, la democracia conllevó, en este caso, una apertura hacia la pluralidad étnica, religiosa, sexual, que permitió disminuir el "costo" de la disidencia (Forni, 1993) a la hora de expresar estilos de vida que se definen como alternativos a una concepción monolítica de la sociedad. Como señala Schenkolewsky-Kroll:

La institución de la democracia en 1983 permitió cambios que estaban latentes y un ajustamiento a la realidad. La sociedad argentina reconoció que no es una sociedad monolítica sino una sociedad basada en la inmigración donde existe un pluralismo legítimo (2001, p.70).

Sin embargo, este contexto no explica de por sí la revitalización religiosa. Realizando trabajo de campo he observado las dificultades por las que pasan quienes asumen un compromiso con la ortodoxia religiosa, al no dejar de sentir el peso de la mirada externa de familiares y amigos que no terminan de comprender el camino que han tomado. En algunos casos, el vivir en otro país, alejado de ese entorno, les permite adoptar ciertos marcadores identitarios, como el cubrirse la cabeza con una gorra o dejarse la barba crecida, reconociendo que no hubieran podido adoptar esa fachada corporal en su país de origen. Por lo tanto, si bien podemos tener en cuenta la importancia de los contextos de multiculturalismo, debemos enfocar en los efectos de un determinado tipo de discurso, puesto en circulación desde las instituciones religiosas, que resignifica los marcadores identitarios vinculados a lo religioso, disminuyendo la distancia simbólica entre la práctica religiosa y un estilo de vida secular. Justamente, son los significados que este tipo de discurso pone en circulación los que permiten a los individuos considerar los estilos de vida basados en perspectivas religiosas como anclados en el mundo moderno, como respuestas a los problemas de la modernidad y afines a modos de identificación con lo judío que no pasan necesariamente por la práctica de la religión.

El proceso de revitalización religiosa en el judaísmo se ha expresado en la cantidad de conversos, judíos no religiosos que modifican sus prácticas y visiones del mundo en el marco de estructuras de plausibilidad (Berger, 1968) que reafirman la evidencia de la identidad religiosa $^{8}$. Se trata de conversiones internas, es decir, realizadas dentro del marco del judaísmo, que no suponen cambios en la pertenencia religiosa. Pero las conversiones son una cara de este proceso, ciertamente enfatizada por los trabajos realizados al respecto, pero que afecta a una minoría de la población judía de Buenos Aires ${ }^{9}$. A esta dimensión, debemos agregar la de la constitución de una red institucional abierta a los judíos no religiosos que habilita una serie de circulaciones y consumos donde los sujetos sienten la libertad de entrar y salir cuando lo desean ${ }^{10}$. Estos judíos no afiliados a 
las instituciones religiosas son percibidos, por parte de la comunidad religiosa, en este caso Jabad Lubavitch, como sectores a los cuales hay que atraer hacia el judaísmo ortodoxo. De ahí la puesta en marcha de diversos proyectos que provocan la salida de la comunidad religiosa hacia el exterior y su creciente visibilización en el espacio público. Uno de los ejemplos principales es el encendido de candelabros gigantes en varias plazas de la ciudad durante la festividad de Jánuca, acontecimiento que se realiza en el marco de un acto central que incluye discursos, espectáculos artísticos y la presencia de funcionarios gubernamentales. Además del acto central en la plaza República Oriental del Uruguay, se llevan a cabo pequeños actos a lo largo de los ocho días de duración de la celebración.

La revitalización religiosa no supone un mero retorno al pasado que deja de lado la dimensión secular del judaísmo. Por el contrario, de lo que se trata es de analizar cómo lo religioso y lo secular construyen sentido interpenetrándose. Cómo circulan los significados, cómo son puestos en escena y administrados, cómo se amalgaman discursos provenientes de diferentes campos y diferentes fuentes de legitimación. Analizaremos este proceso desde la práctica de las leyes dietéticas. Si tomamos estas leyes como foco del análisis es porque las mismas tienden a modificaciones radicales en las prácticas y en las sociabilidades que habilitan (Topel, 2003), constituyendo fuente de tensiones familiares y reorganizando la vida cotidiana del creyente tanto dentro del hogar como fuera de él. Es, por otro lado, uno de los pilares sobre los cuales Jabad Lubavitch y otros movimientos ortodoxos construyen sus discursos respecto al "retorno a las fuentes". Al implicar lo que los propios actores sienten como cambios radicales en los hábitos y las sociabilidades, hay una mayor demanda de legitimaciones. Además, salvo que el actor se sumerja en la comunidad religiosa y decida vivir en su seno, estudiando en una yeshivál ${ }^{11}$ hasta contraer matrimonio y formar un hogar religioso, encontrará que el mundo donde transcurre su vida cotidiana, con sus compañeros de trabajo, su familia y sus amigos, no cumple la función de estructura de plausibilidad.

Para conducir este análisis, debemos, antes que nada, clarificar ciertos conceptos. ¿Por qué utilizamos los términos religioso y secular? ¿Qué significan estos términos y cómo se aplican al caso del judaísmo? Para responder a estas preguntas, se hace necesario un pequeño recorrido histórico.

\section{El judaísmo entre la secularización y la religión}

El siglo XVIII se considera como el inicio de la modernidad judía en Europa, proceso que diversificará los anclajes identitarios en los cuales los judíos podían definir su identidad. De acuerdo a la socióloga Régine Azria:

La modernidad judía se presenta como una ruptura interna que afecta el sistema de autoridad tradicional, su modo de organización comunitario, su sistema de valores y de representaciones, sus símbolos, sus prácticas, sus creencias (Azria, 2003, p.64).

A partir de entonces la identidad judía dejará de estar irremediablemente vinculada a la creencia en Dios y a la práctica de sus preceptos. Si hasta el momento ser judío significaba pertenecer a una nación sagrada, un pueblo que había sido elegido por Dios, y que se relacionaba con él a partir del cumplimiento de sus preceptos, las nuevas corrientes irán corroyendo esta relación para definir a los judíos bajo un discurso nacionalista moderno en el caso del sionismo, un discurso clasista en el caso del 
bundismo, o religioso bajo una Reforma que considera la dimensión religiosa como el núcleo de la identidad judía, dejando de lado la dimensión nacional enfatizada por el sionismo.

La ortodoxia surge como reacción a este proceso, deslegitimando toda innovación en el judaísmo. No se trató de un movimiento homogéneo, pero más allá de sus diferencias, se basó en la reivindicación de la tradición y el rechazo al contacto con el mundo no judío.

A lo largo del siglo XX, fueron las corrientes laicas las que predominaron en el mundo judío, quedando la ortodoxia relegada a posiciones periféricas y defensivas. Diversos acontecimientos dieron lugar a esta particular configuración del campo judaico. Además del desarrollo de una modernidad que prometía el progreso indefinido, llevando a la necesidad, por parte de las religiones, de elaborar estrategias de adaptación y reestructuración interna (Berger, 1968, Kepel, 1995), en el caso del judaísmo podemos señalar otros factores. En primer lugar, el holocausto nazi terminó por destruir a las comunidades que aun funcionaban como estructuras de plausibilidad de una concepción tradicional de la vida judía. Los sobrevivientes tuvieron que reconstruir ese mundo en contextos diferentes como los EEUU, Canadá y Francia (Gutwirth, 2004). Es cierto que éste mundo ya había sido minado desde dentro. Pero el holocausto marcó el declinar de la mayor parte de las comunidades judías de Europa del este, donde a comienzos del siglo XX se concentraba la mayor cantidad de población judía del planeta. Pero otra de las consecuencias del holocausto nazi fue la deslegitimación, y por tanto pérdida de poder simbólico, de los sectores religiosos que se habían opuesto a la inmigración judía a Palestina, núcleo del proyecto sionista secular de creación de un Estado nación ${ }^{12}$. La declaración de independencia de Israel proclamada en 1948 significó la concreción de la utopía de un sionismo hegemonizado por una izquierda laica que gobernó el Estado hasta 1977. A las representaciones que desde el siglo XVIII se venían difundiendo para caracterizar a los judíos tradicionalistas, que resaltaban su arcaísmo, fatalismo y rechazo a la modernidad, (Baumgarten, 2006), se agregó el estigma de no realizar el servicio militar en Israel ${ }^{13}$.

La secularización no significó la desaparición de las prácticas religiosas, sino su resignificación. En un artículo cuya pregunta concierne a cómo se negocia en la actualidad el contacto entre la modernidad y las prácticas judías, Azria (1991) distingue entre dos modos de relación con la tradición. De un lado, quienes ven a la tradición desde el prisma religioso, dotándola de un carácter normativo. Es la opción de los judíos ortodoxos, para quienes el corpus tradicional aparece como una alternativa a la sociedad secular y como un sistema de reglas que deben ser seguidas puntillosamente. Del otro lado, están quienes consideran a la tradición como un elemento cultural, lo que les habilita a elegir, de entre el corpus de prácticas, aquellas que les resultan más significativas. Aquí opera el concepto de bricollage religioso, que coloca al individuo y su subjetividad en el centro del sistema de autoridad religiosa. Para el ortodoxo, las prácticas deben ser cumplidas en su totalidad, ya que el individuo no tendría la capacidad ni el derecho de elegir cuáles son pertinentes y cuáles no. Si la razón divina no puede ser comprendida por la limitada razón humana, el judío debe anularse a la divinidad y realizar los preceptos tal como figuran en los textos diseńados por las fuentes de autoridad que son los tzadikim, los sabios y los justos. Por el contrario, el no ortodoxo considera su subjetividad como fuente de autoridad, priorizándola como tal a la hora de decidir qué prácticas cumplir y cuáles no ${ }^{14}$.

A esta primera distinción, Azria adhiere aquella que se produce entre dos formas de percepción de la relación con la sociedad. Por 
un lado, tenemos una actitud de rechazo a la sociedad secular y no judía, una voluntad de distanciamiento respecto a su sistema de valores. Pero también ocurre que muchos judíos buscan convergencias entre las prácticas judías y las de la sociedad global:

las prácticas judías son entonces consideradas como una de las vías particulares de acceso a lo universal y deben poder prestarse a un cierto número de ajustes funcionales, en el centro de los cuales se encuentra el principio de secularización (Azria, 1991, p.63).

$\mathrm{Al}$ analizar los ajustes funcionales, Azria se pregunta por qué ciertas prácticas son realizadas mientras que otras caen en el abandono. ¿Cuál es el criterio de selección? Su hipótesis es que aquellas que son conservadas son las que satisfacen dos condiciones. Por un lado, el poder desplazar su significación primera para constituirse en vectores de nuevos mensajes, en consonancia con los valores propios de la modernidad. Por otro lado, deben crear lazo social. Ambos criterios suponen una secularización de las prácticas religiosas, es decir, un desprendimiento de su significación anclada en la esfera sagrada cuya centralidad, en el caso del judaísmo, es la divinidad. La secularización se produce por la vía de diversos canales, entre los cuales Azria menciona, a modo de ejemplo, la historia, la ética y la convivencia. Estas esferas funcionan como fuentes de legitimación de las prácticas.

La potencialidad que una práctica tiene de ser legitimada depende de su permeabilidad a la racionalización en el sentido de adaptación de su sentido a los valores de la modernidad. Como tipos de racionalización menciona las lecturas higienistas y medicales concernientes a las leyes dietéticas, la circuncisión y las leyes de pureza familiar, o las lecturas político-sociales del descanso sabático y el jubileo.
En definitiva, la secularización ha modificado el sentido de las prácticas, las cuales pueden ser realizadas con fines diferentes a los meramente religiosos. Los sentidos que rodean las prácticas judías van de lo religioso a lo secular apelando a diversas fuentes de legitimación, y permitiendo el contacto entre judíos ortodoxos y no ortodoxos. A fin de poder dar cuenta de este proceso, Friedman (1991) recurre al concepto de compartimentalización, por el cual entiende la puesta en escena de un mecanismo a través del cual una misma actividad es presentada bajo diferentes lenguajes y niveles de legitimación. Así, los emisarios de Jabad en los campus universitarios en Estados Unidos afirman estar representando al judaísmo histórico, alegando que sus esfuerzos proselitistas tienden a la preservación de una identidad judía entendida como nacional antes que religiosa. Pero en el nivel interno al grupo, la misma actividad se recubre de significado religioso, siendo entendida como parte de un proceso mesiánico. De este modo, el autor sostiene que:

cada compartimento demanda otro lenguaje y código de comportamiento. Sólo compartimentalizando los formatos de las diversas actividades, y diferenciando entre los variados niveles de explicación y legitimación, es que Jabad puede mantener un sistema tan complejo de mutuas relaciones con el mundo judío secular (1991, p.347).

No obstante, las fronteras entre los diferentes compartimentos pueden ser violadas, lo cual genera dificultades en el sistema de relaciones con el mundo judío no ortodoxo.

Este proceso de compartimentalización se realiza en un contexto de fluidez y disolución de fronteras fuertes. Disolución de las fronteras del campo religioso, como plantea Bourdieu (1987). Disolución de las fronteras de aquellos marcos ideológicos que en el siglo XX se vivían 
como excluyentes, lo que permitía anclar una experiencia de lo judaico que hoy día se experimenta más bajo el fundamento de un sentimiento personal, emocional e intelectual (Sorj, 2009). Este proceso deja ver la dialéctica entre la producción de lazos comunitarios fuertes y la disolución de las fronteras. Si una comunidad religioso-ortodoxa con marcadores identitarios y criterios de pertenencia fuertes puede establecer relaciones con los judíos no ortodoxos, se debe a que dicha comunidad actúa en un campo judaico de fronteras fluidas. Quienes asisten a sus actividades no son ortodoxos, y así como pueden escuchar una conferencia de un rabino de Lubavitch, pueden vincularse a instituciones del judaísmo conservador o del reformista, o presenciar conferencias de personalidades judías laicas, sin que para ellos una cosa sea incompatible con la otra.

De lo que se trata ahora es de observar cómo el proceso de interpenetración de lo religioso y lo secular se realiza en función de un proyecto identitario anclado en una visión halájica de las prácticas judías, es decir, una visión que considera que las mismas son preceptos divinos que deben ser cumplidos en tanto tales, negando la subjetivación de la autoridad, pero que no obstante habilita una serie de ajustes funcionales que recurren a las lógicas de matrices discursivas seculares. Como nos concentraremos, principalmente, en las interpenetraciones de matrices discursivas religiosas y medicales, aunque sin por ello dejar de lado otros criterios de legitimación, conviene primero realizar una breve aproximación al tema de las relaciones entre salud y religión.

\section{Las leyes de Kashrut. Un campo para el análisis de la relación entre religión y salud}

La interpenetración de los campos religiosos y medicales ha sido señalado por Bourdieu
(1987), quien observa cómo las fronteras de los campos se han disuelto, conformando un nuevo campo que denomina "de cura de almas", donde la competencia se produce entre agentes diversos como sacerdotes con sotana, médicos, profesores de artes marciales, miembros de diversos grupos religiosos, médicos, sexólogos, profesores de expresión corporal, de deportes asiáticos, consejeros de vida. Se trata del espacio dentro del cual se busca dar sentido a la conducta en la vida cotidiana y a orientar la visión del mundo. La expansión de los límites del campo religioso hacia el campo medical conlleva la lucha por imponer la definición de qué es curar, qué es la enfermedad, qué es la salud, "[1]ucha simbólica por imponer la definición entre el médico, el curandero, el psicoanalista, el sacerdote, el manosanta, el hechicero, todos dicen curar" (Mallimaci, 2001, p.20)

Entre las dimensiones constitutivas de lo religioso en la modernidad, Ari Pedro Oro señala la existencia de una dimensión terapéutica:

En las formas modernas de creer vemos también a lo espiritual articulándose, de maneras diversas, con la búsqueda de la salud, de la realización del equilibrio psíquico y del bienestar en general. (1996, p.67)

Así, numerosas investigaciones han tomado como objeto las relaciones entre las creencias religiosas y la búsqueda de la salud. El pentecostalismo, con su énfasis en las sanidades, ha sido un terreno propicio para este tipo de análisis. Pero la diversidad de medicinas y de especialistas en la salud que ofrecen sus servicios por fuera de las instituciones hegemónicas en el campo medical conforman una red que se interrelaciona con sistemas de creencias vinculados tanto a la New Age como a filosofías orientales ${ }^{15}$. Las relaciones entre salud y religión en el judaísmo han sido menos exploradas, en parte porque de por sí el judaísmo ha sido menos abordado en su faceta religiosa que, por ejemplo, el pente- 
costalismo. Un interesante análisis entre salud y religión en una población de lubavitchers ha sido realizado por Dein (2004), quien observa cómo los adeptos a la filosofía jabadiana están expuestos tanto a ideas religiosas como seculares respecto al cuerpo y la enfermedad. Es decir, el cuerpo es visto tanto desde un punto de vista místico como naturalista. Que conozcan el modelo místico, a través de la lectura de los textos sagrados, no implica que dejen de pensar bajo el modelo naturalista y que en caso de enfermedades no severas recurran a medios pragmáticos antes que mágico- religiosos ${ }^{16}$. Sólo cuando la ciencia deja de dar respuestas, acuden a medios religiosos como la escritura de cartas al rebe o la revisación de los tefilin.

\section{Discurso medical y discurso religioso en la construcción del sentido del Kashrut}

Analizaremos ahora el solapamiento de significados observado a través de mi trabajo de campo en la institución Jabad Lubavitch de Buenos Aires. Las observaciones las he realizado en la sede central del movimiento, ubicada en la zona conocida como Barrio Norte, pero que desde el punto de vista catastral corresponde al barrio de Recoleta. Mi trabajo de campo consistió, básicamente, en la realización de observación participante, entrevistas en profundidad y análisis de revistas y folletos. Comenzaré refiriéndome a una serie de conferencias acerca del tema del Kashrut.

La institución organizó, a mediados del 2004, una serie de cuatro conferencias cuyo tema era la alimentación casher. La primera fue dictada por un rabino, especialista en el tema, que explicó los modos en los cuales los alimentos eran tratados y elaborados de manera de garantizar su condición de alimentos permitidos. La segunda fue conducida por una médica psiquiatra especialista en obesidad y trastornos de conducta alimenticia, a la cual, en el presente trabajo, designaremos como "doctora P". La tercera conferencia estuvo a cargo de un miembro de la institución, y el tema de la misma fue la relación entre Kashrut y shabat, el día sagrado en el judaísmo. Finalmente, el cierre fue oficiado por un rabino de Jabad. A los fines de este trabajo, corresponde concentrarse en la segunda y cuarta conferencia, cruzando los datos con otras observaciones y análisis de folletos.

Lo que quisiera destacar es el modo en el cual la institución, al convocar a un miembro del campo de la medicina, apela a un saber profano. Efectivamente, este saber médico es incorporado al cuerpo de discursos que legítimamente circulan por la institución religiosa. Sin embargo, como se verá más adelante, la relación entre el saber médico y el religioso es de complementariedad, pero en una tensión permanente.

El Kashrut está atravesado por variadas significaciones que se ponen en escena a través de los discursos emitidos por diferentes actores. El discurso médico confiere sentido a las leyes dietéticas en el marco de un diagnóstico general de la sociedad y de los males que aquejan a las personas. Se sostiene que la depresión y los ataques de fobia se relacionan con determinados estilos de alimentación que afectan a la autoestima, a la valoración que la persona hace de sí misma. En el discurso medical, tal como fue expuesto por la doctora P., Kashrut es sinónimo de una vida saludable. Es decir: comer casher es comer sano. Se recalcan las consecuencias positivas que una dieta basada en dichos principios tiene sobre el cuerpo y la psiquis de cada individuo. La sistematicidad exigida en el cumplimiento del Kashrut apuntaría a mejorar diversos aspectos de la vida terrenal, como ser la salud física y psíquica, la autoestima, el estado de ánimo, las relaciones familiares. Las consecuencias de una vida a-sistemática serían las enfermedades como el stress, el asma, el colon irritable, la 
anorexia y la bulimia, así como las fluctuaciones en el estado de ánimo, la angustia, la sensación de culpabilidad por no poder controlar los impulsos y la dificultad en lograr autonomía respecto a los semejantes.

El Kashrut se relaciona con el cuidado de sí mismo que se realiza en el seguimiento de un plan alimenticio donde el componente de cada alimento es un factor fundamental. La alimentación es entendida desde su dimensión holística, donde el alimento no tiene sólo influencias en lo orgánico, sino también en el alma y en las conductas:

los alimentos, les repito, ejercen una influencia decisiva, no solamente en el cuerpo sino a nivel espiritual, intelectual, y de los sentimientos. Se dice que somos lo que comemos, y de alguna manera, se convierte en carne y sangre de nuestra persona al ingerirlo ${ }^{17}$.

Así, si las leyes de Kashrut señalan como alimentos permitidos los animales con rumia, es por sus consecuencias en los planos psicológicos y espiritual, que en discurso aparecen confundidos:

Desde lo psicológico, digamos, desde lo espiritual, la Torá nos está hablando de poder incorporar animales que tienen la capacidad de rumiar, o sea, de repensar, de analizar, reflexionar, o sea que esta rumia que en el animal es del tubo digestivo, se transforme en el ser humano, en una función del cerebro. Y de esta manera incorporamos con este tipo de animales, una característica que es fundamental para todo judío. Por eso, cuando estamos hablando de alimentos casher, o de comer casher, estamos aceptando un alimento que es sano espiritualmente. Todos estos alimentos nos predisponen de mayor energía, ¿por qué lo digo?, es un alimento mucho menos tóxico, se absorbe mucho más rápidamente, y de alguna manera nos están alejando del mal, de los malos rasgos, y yo diría de los malos hábitos también. ${ }^{18}$

Las leyes alimenticias son interpretadas en un registro que combina lo espiritual con el funcionamiento orgánico del cuerpo:

otros alimentos prohibidos pueden ser, por ejemplo, no ingerir sangre del animal. A grandes rasgo ustedes saben que en la sangre del animal está el alma, está de alguna manera la característica crucial. Al ingerirla se fusiona con nuestra sangre, o sea que lo que se quiere evitar es justamente que el ser humano se bloquee emocionalmente, que tenga actitudes o conductas de alguna manera salvajes. Por eso están prohibidos los animales salvajes. Por último, [respecto a] la prohibición de mezclar carne con leche, también sabemos que cuando comemos carne esperamos seis horas [para consumir lácteos] Esas seis horas, ¿por qué son? La carne tiene un tiempo de digestión mucho más largo, más prolongado, con lo cual quedan carne en los dientes, queda muchas veces como un gusto a grasa en la boca. Y luego de la carne, tomar leche entorpece la digestión. ${ }^{19}$

Estos argumentos aparecen en un folleto editado por la institución, cuyo título refiere a los beneficios de la alimentación casher desde la óptica secular: "Libre de impurezas, libre de contaminantes, libre de crueldad animal, ¡Casher!”. Al título le sigue la foto de un niño sonriente con una hamburguesa en sus manos. Como puede observarse, las legitimaciones a las que se recurre refieren a la distinción entre alimentos saludables y dañinos y a formas de moralidad vinculadas con un discurso ecológico más que a la que se establece entre lo permitido y lo prohibido de acuerdo a la legislación religiosa. La imagen de la hamburguesa es una forma de mostrar que lo casher puede ser compatible con un estilo de alimentación propio a 
la moderna sociedad de consumo. Es posible comer como judío sin que ello signifique comer la comida típica judía. La religiosización conlleva entonces la desetnicización. Volveremos sobre el análisis de los folletos.

El discurso religioso, que en el ciclo de conferencias fue expuesto por un rabino, conecta el Kashrut con la idea de un Dios que ha creado el mundo y ha otorgado al hombre el "manual de instrucciones" para conducirse con éxito. Pero la existencia en el mundo terrenal tendría la función de elevar al ser humano mediante su conexión con la fuente de su creación, conexión que se logra a través de la realización correcta de los actos de la vida cotidiana, entre ellos el de alimentarse. Por otro lado, el Dios que ha creado el mundo ha elegido a su pueblo y le ha obligado a mantenerse en su particularidad. Comer casher no debe ser visto como un mandato dirigido a toda la humanidad, sino como una marca distintiva del pueblo de Israel y una barrera de protección ante la amenaza del contacto con los otros pueblos. Finalmente, las leyes del Kashrut no tienen, para la limitada mente humana, lógica alguna. Deben ser cumplidas porque Dios así lo ordena. Detrás de este conformismo el judío expresa su voluntad de vivir como un siervo de Dios. Sin embargo, a pesar que desde la lógica religiosa estas leyes no tienen explicaciones, vemos cómo la estrategia de los movimientos religiosos consiste en la utilización de fuentes de legitimación más allá de lo religioso a fin de explicar y conferir sentido a esta práctica.

Pueden encontrarse similitudes entre el discurso medical y el religioso. Ambos apelan a la modificación del sujeto en sentido cuasi ascético, al desarrollo de un sistema de vida donde el autocontrol y la moderación se constituyan en características primordiales. Como sostiene la doctoras P: "con esta elección que nosotros hacemos respecto a lo que se debe y lo que no se debe, no solamente estamos haciendo una elección con respecto al alimento, también estamos aprendiendo de alguna manera a controlarnos y a moderarnos". Las licencias respecto a esta postura ascética son interpretadas, desde la medicina, como patología, y desde la religión, como alejamiento de la santidad.

A fin de desarrollar este último concepto, me remitiré a conversaciones que tuve con rabinos de Jabad Lubavitch a lo largo de mi trabajo de campo, donde hablamos de la dificultad de alcanzar los estados de ascetismo y santidad propios de un josid ${ }^{20}$. En estas conversaciones, se ponían ejemplos que remitían a los modos de alimentarse. Una historia bastante difundida en el círculo jabadiano cuenta que el padre fundador de Jabad, Shneur Zalman de Liadi, quien se había volcado hacia el jasidismo gracias a su contacto con el Maguid (predicador) de Mezrich, sucesor del Baal Shem Tov, fundador del jasidismo, invitó a cenar a su casa a un rabino. Este rabino se quejó de que la comida tenía demasiada sal, a lo que Shneur Zalman respondió que, tras haber pasado un tiempo con el Maguid, había dejado de sentirle el gusto a la comida. No sentir el gusto a la comida era una expresión del grado de desapego respecto a lo material, de la santificación de la persona. Para muchos lubavitchers, que no han alcanzado semejante grado de santidad, el concepto de Itzkafie viene a ser el eje a través del cual se desconectan de los placeres de la existencia material, una renuncia al placer. Comer sin condimentos, o tomar agua hervida en vez de café o te, es un modo de exteriorizar esta postura de rechazo al placer material. Actitud difícil, pero que es vivida como un desafío: "hay que trabajarse permanentemente a uno mismo", me decía un rabino. Para explicarme a qué se refería, me puso el ejemplo de otro rabino, muy admirado y respetado dentro de la comunidad: "cuando fui a comer a su casa, no podía creerlo. Tenía delante de él un pollo excelente, del cual probaba unos bocados para luego dejarlo a 
un lado. Luego nos sirvieron un postre. Yo no podía para de comer, pero él apenas lo tocó”. Obviamente, no se trataba de que el postre no le gustara, sino de realizar un trabajo en clave ascética a fin de que el acto de alimentarse fuese una vía de santificación.

Las diferencias entre el concepto de sistematicidad en la organización de la vida que propone el discurso médico y el que propone el religioso radican en las recompensas aparejadas. El discurso medical pone el énfasis en alcanzar una vida saludable donde el cuerpo y la mente del individuo es el principal objeto sobre el que se actúa. Ofrece autoestima, salud, buena digestión de los alimentos. Por su parte, el discurso religioso no sostiene la necesaria equivalencia entre el cumplimiento de los preceptos divinos y el bienestar en este mundo. Si bien el vivir de acuerdo a la voluntad de Dios trae bendiciones, no faltan las historias de grandes tzadikim cuyas vidas han estado signadas por un sufrimiento aceptado con la alegría de saber que nada malo podía provenir de Dios.

Mientras que el discurso medical apela al individuo, el religioso hace un hincapié especial en el pueblo y en la necesidad de crear barreras para protegerlo del exterior. Si se dirige al individuo, es siempre en tanto parte del pueblo judío y portador de un "alma divina". El discurso medical relaciona el Kashut con beneficios que pueden aplicarse a cualquier ser humano, mientras que el religioso se limita al miembro del pueblo judío, sosteniendo que un nacido de vientre gentil, incluso comiendo casher, no puede mantener la conexión con la divinidad que un judío, mediante el mismo acto, puede lograr. Esto es así porque, de acuerdo a Jabad, hay una diferencia de naturaleza entre uno y otro.

Analizando la conferencia dictada por el rabino de Jabad, observamos una actitud hacia el acto de la alimentación que difiere, al enfatizar en el componente sobrenatural, del discurso médico. En el caso de este último, lo sobrenatural aparecía bajo categorías como el alma y lo espiritual, cruzadas por el concepto de bienestar. De lo que se trataba era de señalar las "actitudes comportamentales" que afectaban al bienestar del hombre, no sólo en el aspecto físico, sino también en el espiritual. Por su parte, la conferencia del rabino, centrada en lo sobrenatural, enfatizó la figura de Dios y de la energía divina, apenas mencionadas en el discurso médico. Si hasta el momento las conferencias se habían centrado en la relación entre la alimentación y la salud, con la intervención del rabino se redefinía, mediante la incorporación de referencias a la divinidad, el sentido del acto de la alimentación. El fin último del mismo dejó de ser la obtención de bienestar en lo referente a la salud, pasando a ser el servicio a Dios:

y entonces tuvimos la segunda clase, donde a todos nos encantó escuchar cómo el casher es salud y cómo no solamente la comida kosher, sino que la actitud casher, adecuada, es la que permite mens sana in corpore sano, tener realmente y gozar de un cuerpo sano, obviamente para servir a Dios. Dios nos mandó a este mundo con un propósito, y nosotros cuando tengamos que rendir cuentas a los ciento veinte años, no queremos quedar mal con quien confió tanto tiempo y nos dio sustento y nos dio todo lo que necesitamos para poder llegar a cumplir con esa misión." ${ }^{21}$

De este modo, la salud física deja de ser un fin en sí mismo. Se convierte en un medio para cumplir con la misión de servicio divino.

Si la promesa de una vida saludable integra un discurso legitimador de las leyes del Kashrut, la vida religiosa conlleva prácticas que no necesariamente se adecuan a lo que podemos definir como una actitud sistemática en la búsqueda de la salud. Como bien saben los lubavitchers, más allá de lo que figure en los 
folletos, el que un alimento sea casher no significa que sea, de por sí, saludable. Cuando le pregunté a un rabino acerca de las propiedades de la hamburguesa del Mc Donald's casher ${ }^{22}$, respondió con una sonrisa cómplice que sus efectos sobre el organismo eran casi tan nocivos como el de la hamburguesa treif ${ }^{23}$ : "a lo sumo, [comiendo la hamburguesa casher] vas a vivir un día más", afirmó. En efecto, comer una hamburguesa casher le permitía al judío obedecer la ley divina, pero eso no significaba el cuidado de su organismo. No obstante, en ninguna parte del complejo sistema de leyes religiosas judías se hace mención a las hamburguesas de Mc Donald's. No hay obligación de comerlas. Pero el judío sí se siente en el compromiso de organizar una comida especial en shabat. No pretendemos en éste trabajo definir qué es un tipo de alimentación sano y qué no lo es. Pero es interesante observar cómo los mismos actores perciben las distancias entre ciertas promesas y ciertas prácticas. Justamente, en un almuerzo de shabat, donde las personas estaban claramente comprometidas con llevar "estilos de vida saludables", y donde se habló de temas como el yoga y la alimentación, la dueña de casa, tras servir el postre y el café, expreso: "este brownie es tan poco saludable como uno treif". Marcaba, de este modo, que comer casher podía no tener ningún tipo de repercusión en la salud, o incluso podía tener el mismo efecto negativo que comer treif, por lo que casher y salud no estaban inevitablemente vinculados.

Los farbrenguen son reuniones jasídicas que constan de tres elementos: la entonación de cantos, las palabras de Torá y los lejaim. Estos últimos son brindis generalmente con vodka, aunque también se suele tomar whisky, y se van repitiendo a lo largo del farbrenguen. Los propios actores son conscientes de que no se trata de una práctica saludable, al menos en el aspecto físico. El sumergirse en una filosofía jasídica no implica, como vemos, permanecer ajenos al sistema de representaciones bajo el cual se clasifican ciertas conductas como saludables o no. Al igual que la sociedad exterior, entienden que tomar vodka pura en cantidades no es bueno para la salud. Del mismo modo, cuando un rabino tiene prohibido por el médico tomar alcohol, realizará el kidush ${ }^{24}$ con jugo de uva, sin que se le ocurra pensar que, por el hecho de cumplir un precepto religioso, una suerte de milagro atenuará los efectos nocivos del vino.

\section{Sentidos permitidos y administración de los significados}

Nuestro objetivo no es sólo comparar dos matrices discursivas, sino analizar cómo, desde un proyecto identitario religioso, se construye sentido respecto a las prácticas judías incorporando y administrando las fuentes de legitimación de otros campos.

Al convocar a un miembro del campo de la medicina, la institución habilita un discurso ante el cual, sin embargo, reacciona. Dicho corpus discursivo, más allá de su expresión sistematizada en la intervención de la doctora P., recorre el campo judaico bajo la forma de concepciones difusas, sentido común, frases hechas. Se trata de un discurso que asigna a los mandatos divinos objetivos terrenales, que implica una secularización del judaísmo. En este sentido, la prohibición de ingerir carne de cerdo respondería al problema de la triquinosis, así como los fines de la circuncisión remitirían a una cuestión de higiene.

A lo largo de las observaciones que he realizado en el campo, pude observar cómo los representantes del saber religioso reaccionan ante semejantes discursos, afirmando que: "las leyes del kashrut no nos fueron dadas, como se nos quiso hacer creer durante tanto tiempo, por el tema de la triquinosis. En todo caso, eso [las consecuencias positivas en la salud] sería 
la yapa." 25 Se insiste en que los beneficios que las leyes religiosas pudieran tener en lo que respecta a la salud, tienen utilidad tan sólo para "legitimarnos ante los otros", ${ }^{26}$ pero no son la verdadera razón por la cual Dios ordenó su cumplimiento.

La articulación de discursos se observa, como hemos mencionado más arriba, al analizar algunos folletos distribuidos dentro de la institución. En uno de ellos, puede leerse lo siguiente:

El experto gastrónomo estadounidense Dr. Myles Bader escribe, 'Si deseas un pollo sano, con buen sabor, compra kosher'. A los pollos kosher se los sumerge en agua helada durante $30 \mathrm{mi}$ nutos, se los sala para quitarles la sangre y se los lava luego tres veces para quitarles la sal. Como el pollo contaminado es la causa del $48 \%$ de las intoxicaciones, este proceso podría literalmente salvar vidas." 27

Como puede verse, se apela al saber de un experto gastrónomo, el cual, desde un campo secular, aporta un discurso que legitima las prácticas propias del campo religioso. Sin embargo, desde el campo religioso debe administrarse dicha legitimación, ya que se corre el riesgo de que la misma, al enfatizar en los beneficios concernientes a la salud, termine por relegar los componentes sobrenaturales que conforman las representaciones religiosas. De ahí que el párrafo que continúa al anteriormente citado resalte que: "Las leyes de kashrut no fueron creadas por razones de salud física. Pero no resulta sorprendente que lo que es bueno para el alma termine siendo bueno para el cuerpo también." 28

Este proceso de administración de las legitimaciones seculares pueden observarse en la conferencia dictada por el rabino en el ciclo de conferencias. En la misma se insistió en que la fuente de alimentación del hombre no era la comida, sino la energía divina que en ella se manifestaba cuando la santificábamos mediante la pronunciación de una bendición. De este modo, el acto de alimentarse constituía una de las vías de apego a Dios, del mismo modo que el mantenimiento de la salud no tenía como fin último el bienestar de la persona, sino el servicio al Creador:

\begin{abstract}
Parecería ser que el vivir no depende de comer, depende de estar apegados a Dios o no. Esto es totalmente distinto de lo que venimos hablando hasta ahora, porque estamos muy preocupados en lo que comemos y en lo que bebemos. No es que no hay que preocuparse y no hay que saber lo que comemos y bebemos. [...] Pero, ¿esto es lo que nos alimenta?"29
\end{abstract}

Recurriendo a las fuentes religiosas, concluye que lo que mantienen viva a la persona es la palabra divina, la misma con la cual fue creado el mundo.

Como podemos observar, la institución habilita la circulación de discursos no religiosos y la presencia de profesionales de la salud, a fin de construir la legitimidad de las prácticas religiosas. La noción de que casher es salud forma parte de este procesos de secularización de lo religioso mencionado por Azria. La reacción a este discurso no es su mera oposición en función de una legitimidad religiosa, sino su administración, de modo que las legitimaciones seculares sean envueltas por el manto de la matriz discursiva que ponen en escena los profesionales del saber religioso.

\section{Otras fuentes de legitimación. Memoria, supervivencia y mercado}

Al referirnos a la construcción del sentido del Kashrut nos concentramos en la articulación entre religión y medicina, central en el discurso 
religioso. A la vez, la idea de que casher es salud forma parte del conjunto de representaciones que circulan en el campo judaico. Cuando un judío secular escucha este argumento, si ha sido socializado en el campo judaico, ya sabe de lo que se le está hablando. Ha escuchado, probablemente, varias veces que la prohibición de la carne porcina tiene como objetivo prevenir la triquinosis, o que el lavado ritual de manos antes de comer apunta a prevenir enfermedades, como las pestes que asolaron la Europa medieval. Él mismo concuerda con que comer casher es más saludable que comer treif. A la vez, los ortodoxos saben que los seculares se representan el Kashrut de esta manera. Al remitirse a discursos del campo medical, entran en sintonía con las representaciones seculares portadas por los judíos no religiosos, y desde el marco representacional de estos, reorganizan los sentidos sobre el Kashrut.

Pero no se trata sólo de recurrir al discurso medical. Hay otras vías de legitimación, que no se corresponde con la medicina pero sí con el entramado de significados a través del cual los judíos se piensan a sí mismos.

En uno de los folletos informativos, se afirma que "la judeidad moderna ha debilitado su observancia del 'Cashrut', precisamente en una época en la que, de hecho, como nunca jamás antes, es tan fácil obtener alimentos casher" ${ }^{\prime 30}$. Se contrasta esta época de diversificación del mercado casher con la de siglos atrás, donde mantener una vida basada en el judaísmo representaba un difícil desafío: “EEl modo de vida de nuestros antepasados, mantenido con real sacrificio, debe ser dejado de lado así porque sí?", se preguntan en el mismo folleto. La mención al sacrificio de los antepasados remite al recuerdo de la vida judía en contextos donde el ser judío era objeto de estigmatización. El recuerdo del pasado conforma una memoria de la desgracia. En efecto, los judíos habrían mantenido sus estilos de vida con sacrificio, en ambientes hostiles de persecución y progroms que habrían culminado en el holocausto nazi. Ahora que los judíos viven en contextos plurales, donde pueden vivir como tales sin temor a la persecución, ¿olvidarán el sufrimiento de sus antepasados? El abandono de la alimentación casher es denunciado como una suerte de traición ante el sufrimiento de los antepasados, que habrían pagado con sus vidas su apego a dichas leyes. En efecto, aunque no se mencione el holocausto en sí mismo, la sola mención al sacrificio de los antepasados remite a una serie de imágenes donde se combinan la pobreza, la marginación, las expulsiones y, como corolario, la matanza hitleriana. Aquí observamos la puesta en escena de una legitimación por apelación a la memoria, que es una memoria de la tragedia, una memoria que, como sostiene Candau esta "siempre lista para atormentar a los individuos y los grupos que se consideran sus guardianes" (2001, p.152). Comer casher, además se ser saludable y de ser un precepto divino, es resignificado como modo de honrar a los muertos. Deber de memoria que, desde la segunda mitad del siglo XX, conforma un polo central de identificación con el judaísmo (Azria, 2003)

Uno de los tópicos que recorren el complejo de significados que denominamos universo simbólico judío, es la persistencia del pueblo a lo largo del tiempo. Es común, en las diversas instancias del campo judaico, toparse con discursos que enfatizan cómo el pueblo judío ha sobrevivido a lo largo de centurias mientras que otros, más poderosos, han caído. El discurso religioso retoma este tópico, explicando que esta supervivencia se debe al apego a las prácticas religiosas:

El pueblo judío ha perdurado a través de centurias -mientras otras naciones surgieron y dejaron de existir- a pesar de una persecución sin paralelos. Este es un hecho histórico que desafía cual- 
quier explicación racional. Hemos sobrevivido únicamente por habernos sujetado con garras y uñas a nuestras sagradas y divinamente inspiradas tradiciones. ${ }^{31}$

El tema de la supervivencia a pasar de las persecuciones forma parte de otras matrices discursivas dentro del judaísmo, no necesariamente religiosas. Podemos encontrarlo en algunos discursos que emergen de la matriz sionista. A la vez, el aferrarse a las tradiciones no necesariamente remite a una matriz religiosa. Un judío secular puede conectarse con el judaísmo desde una percepción de que sus acciones se vinculan a una tradición milenaria. Lo que sí forma parte de la matriz religiosa es el reconocimiento de que estas tradiciones son "sagradas y divinamente inspiradas". Así, el discurso religioso se monta sobre preocupaciones propias del judaísmo secular, como la supervivencia del pueblo judío, afirmando que "[a]l observar las leyes de "Kashrut", fortalecemos la integridad de nuestras familias, la seguridad de Israel y la unidad de la nación judía en todo el mundo" 32 . De este modo, se sumerge en el proceso de lucha por la instalación del sentido legítimo dentro del campo judaico. La supervivencia ya no dependería del mantenimiento de una cultura basada en el idish, como en su momento propugnaban los bundistas, o de la existencia del Estado de Israel, como sostienen quienes se reconocen ideológicamente en el sionismo. Si ésta cultura y la existencia de Israel son centrales en un movimiento como Jabad Lubavitch, no son factores que de por sí sean entendidos como garantes de la continuidad. La continuidad y la supervivencia se garantizan en el cumplimiento de los preceptos divinos, es decir, en el reconocimiento de que el judaísmo no puede separarse de Dios. En todo caso, la existencia de Israel es función, también, de la conexión con la divinidad.

Finalmente, otra fuente de legitimación se constituye al señalar el crecimiento del merca- do Kosher. Es este crecimiento lo que refutaría la idea de que comer casher es anticuado. Así, el folleto señala el "[í]ndice de crecimiento del mercado kosher en Argentina: 26\% anual, en EEUU: $15 \%$ anual. Más de 400 productos certificados kosher en Argentina. 85 empresas nuevas certificadas kosher en el último año."33

\section{Conclusión}

Nos habíamos referido al concepto de compartimentalización, que mostraba cómo una misma práctica era dotada de diferentes significados. ¿Qué significa comer casher? Desde un compartimento, es cumplir con los preceptos de Dios. Desde otro, es cuidar la salud. Desde otro es cumplir con el deber de memoria, recordando el sufrimiento y reivindicando la resistencia de los antepasados. Es también asegurar la existencia del pueblo judío, interés que no se reduce meramente a lo religioso, sino que conlleva un componente de percepción de la existencia de un pueblo definido por particularidades que van más allá de la religión. Puede ser, también, incorporarse en un mercado en crecimiento.

Jabad Lubavitch busca incorporar todos estos compartimentos en su discurso. El riesgo que corre es que los significados seculares se independicen de su anclaje religioso. Así, Jabad administra los significados, de manera tal de mostrar cómo cada uno de ellos depende, al fin de cuentas, de su anclaje en lo religioso.

Para los movimientos religiosos, la apelación a los discursos seculares es un modo de mostrar que la práctica religiosa no es arcaica, sino que responde a problemáticas actuales como el cuidado de la salud y la supervivencia del pueblo. Así, estas prácticas se legitiman desde una apelación a los recursos simbólicos de otros campos y compartimentos. Pero a la vez, esta reutilización de discursos seculares com- 
porta el riesgo de hacer olvidar la base divina que, para los religiosos, constituye el fundamento de las prácticas judías. Por lo tanto, los movimientos religiosos recurren al saber secular y lo administran. Es necesario que los significados que estos saberes ponen en circulación sean "controlados" a través de los tópicos del discurso religioso. Se trata de una circulación de significados habilitada por la institución religiosa y a la vez administrada por ella, lo que no quita que los propios individuos puedan construir sus propios marcos de sentido apropiándose, a su manera, del discurso religioso.

\section{Religious and secular discourses in the legitimation of religious practices. Jewish dietary laws}

abstract This paper analyze the process by which the religious Jewish movement Habad Lubavitch shapes the meaning of the Kashrut (Dietary Laws), turning to legitimations that came from medical field and seculars discourse matrix linked to the memory of tragedy and the subject of Jewish people survival. The objective in to analyze continuity patters between secular and religious dimensions in proselytizing movements strategies of placement in Jewish field. In order to legitimate religious practices, Habad Lubavitch resorts to secular meanings. Putting in circulation this meanings, risks of emphasize secular aspects of religious practices are posed. In order to avoid this, circulation of meanings is administrated by the movement.

keywords Judaism. Secularization. Legitimation. Habad Lubavitch. Kashrut.

\section{Notas}

1 Entendemos por concepción halájica aquella que define el judaísmo como un sistema de vida basado en leyes divinas que regulan los comportamientos, constituyendo así una ortopraxis. La Halajá es el conjun- to de leyes tal como ha sido codificado en los textos sagrados.

2 Utilizamos el concepto de campo formulado por Bourdieu (1971), para referirnos a un espacio de posiciones relativas donde los agentes compiten por detentar la definición legítima del judaísmo.

3 Las leyes del Kashrut regulan el acto de la alimentación distinguiendo los alimentos permitidos de los prohibidos, así como sus combinaciones permitidas y prohibidas.

4 La revitalización de la ortodoxia en el campo judaico se ha basado en la emergencia de movimientos que ejercer una suerte de proselitismo entre los propios judíos, sin pretender convertir al judaísmo a personas provenientes de otras religiones. Cabe señalar que el concepto de proselitismo no es aceptado por los propios actores sociales comprometidos con estas acciones, que definen sus acciones bajo el concepto de mivtzoim (campañas).

5 Para una discusión acerca de la pertinencia del concepto de comunidad ver Dimentstein (2009).

6 Algunas breves notas sobre el origen del Jabad Lubavitch en Argentina pueden encontrarse en Strusberg y Álvarez, 2003, Bianchi, 2004, Setton, 2008.

7 Líder de un grupo jasídico. En los años cincuenta asume el liderazgo de Jabad Lubavitch Menajem Mendel Schneerson. Los miembros de Jabad lo llaman, simplemente, el rebe.

8 La pertinencia del concepto de conversión ha sido discutida por varios autores. Ver en especial Prandi (2000) y la discusión de Topel (2005) respecto a la validez de su perspectiva en el caso del judaísmo ortodoxo.

9 Sobre la conversión al judaísmo lubavitch en argentina ver Libertela (2004)

10 Fidel y Weiss (2009) han trabajado esta problemática en relación a la juventud enfatizando el concepto de consumo. En relación a las relaciones entre las instituciones religiosas y la juventud judía no religiosa ver Setton (2006, 2009)

11 Escuela religiosa

12 Este tema queda bien ejemplificado en las relaciones entre el sector sionista y el partido ortodoxo Agudath Israel en la Palestina del mandato británico (Friedman, 1995)

13 Esta, como toda representación, conlleva efectos sociales más allá de su grado de adecuación a la realidad. Es cierto que cuando David Ben Gurión realiza 
el pacto, conocido como status quo, con los sectores ortodoxos, permite a los estudiantes religiosos no realizar el servicio militar. Esto no quita que no hayan habido judíos ortodoxos participando en el frente de batalla durante las guerras entre Israel y el "mundo árabe".

14 Varias entrevistas realizadas durante el trabajo de campo permiten observar cómo las personas afirman su derecho a seleccionar del corpus de prácticas aquellas que les resultan adecuadas, considerando otras como ridículas o anticuadas (Setton, 2006).

15 A fin de profundizar en estas temáticas, ver Carozzi (2000) e Idoyaga Molina (2005).

16 En el caso del jasidismo, la acción mágica es interpretada como religiosa, y el mago y la autoridad religiosa se concentran en la misma persona).

17 Conferencia doctora P., 2004.

18 Idem.

19 Idem.

20 Los lubavitch se definen a sí mismos con el término josid, antes que como religiosos u ortodoxos.

21 Conferencia del rabino L, 2004.

22 La firma Mc Donald's inauguró en Buenos Aires un puesto de comidas casher, donde vende sus productos pero adaptados a las leyes religiosas.

23 No casher.

24 Ritual de santificación del shabat.

25 Observación de campo, 2004.

26 Idem.

27 Folleto: "Un menú de primera".

28 Idem.

29 Conferencia rabino L, 2004.

30 Folleto: "Libre de impurezas, libre de contaminantes, libre de crueldad animal, ¡Casher!"

31 Folleto: "Un menú de primera".

32 Idem.

33 Idem.

\section{Referências Bibliográficas}

AVIAD, Janet. Return to Judaism: Religious renewal in Israel. Chicago and London: The University of Chicago Press, 1983.
AZRIA, Régine. Pratiques juives et modernité. Pardés, Paris, n. 14, p. 53-70. 1991. Le judaïsme. Paris: La découverte, 2003.

BAUMGARTEN, Jean. La naissance du hassidisme. Paris: Albin Michel, 2006.

BIANCHI, Susana. Historia de las religiones en la Argentina - Las minorias religiosas. Buenos Aires: Sudamericana, 2004.

BERGER, Peter. El dosel sagrado. Traducción de Néstor Migues. Buenos Aires: Amorrortu, 1968.

BOURDIEU, Pierre. Genèse et structure du champ religieux. Revue française de Sociologie, Paris, vol XII, p.295-334. 1971.

La dissolution du religieux. In: BOURDIEU, P. Choses dites. Paris: Éditions de minuit, 1987. p. 117123.

CANDAU, Jöel. Memoria e identidad. Traducción de Eduardo Rinesi. Buenos Aires: Del Sol, 2001.

CAROZZI, María Julia. Nueva era y terapias alternativas Construyendo significados en el discurso y la interacción. Buenos Aires: Universidad Católica Argentina, 2000.

DANZGER, Herbert. Returning to tradition - The contemporary revival of Orthodox Judaism. New York and London: Yale University Press, 1989.

DEIN, Simon. Religion and healing among the lubavitch community in Stamford Hill, North London - A case study of Hasidism. Lewiston NY: The Edwin Mellen Press, 2004.

DIMENTSTEIN, Marcelo. Algunas reflexiones sobre el uso del término "comunidad" para referirse a los judíos. In: CHIROM, D. (et.al.). Nuevas voces para una nueva tribu. Buenos Aires: Milá, 2009. p. 44-47.

FIDEL, Cynthia; WEISS, Tamara. Marcos para jóvenes en judíos en edad universitaria: objetos de consumo y oferta cultural; modelos identitarios. In: CHIROM, D. (et.al.). Nuevas voces para una nueva tribu. Buenos Aires: Milá, 2009. p. 68-90.

FORNI, Floreal. Nuevos movimientos religiosos en Argentina. In: FRIGERIO, A. (Comp.). Nuevos movimientos religiosos y ciencias sociales (II). Buenos Aires: Centro Editor de América Latina, 1993. p. 7-23.

FRIEDMAN, Menachem. Habad as messianic fundamentalism: From local particularism to universal Jewish mission. In: MARTIN, M; SCOTT APPLEBY, R. (Eds.). The fundamentalism project, vol. 4. Chicago and London: The University of Chicago Press, 1991. p. 328-357.

. The structural foundation for religio- political accommodation in Israel: fallacy and reality. In: TROEN, I; LUCAS, N (Eds.). Israel, the first decade of in- 
dependence. New York: State University of New York Press, 1995. p.51-81.

GRUMAN, Marcelo. Sociabilidade e aliança entre jovens judeus no Rio de Janeiro. 2002. Dissertação (Mestrado) - Universidade Federal Rio Grande do Sul (PPGSA), Rio de Janeiro, 2002.

GUTWIRTH, Jacques. La renaissance du hassidisme. De 1945 à nos jours. Paris: Odile Jacob, 2004.

IDOYAGA MOLINA, Anatilde. Reflexiones sobre la clasificación de medicinas. Análisis de una propuesta conceptual. Scripta ethnologica, Buenos Aires, Vol XXVII, p. 111-147. 2005.

KEPEL, Gilles. La revancha de Dios. Traducción de Marcelo Cohen. Madrid: Anaya \& Mario Muchnik, 1995.

LIBERTELA, Malena. La conversión al judaísmo ortodoxo en una institución de la Ciudad de Buenos Aires. El caso de Jabad Lubavitch. 2004. Tese (Licenciatura) - Facultad de Ciencias Sociales, Universidad del Salvador, Buenos Aires, 2004.

MALLIMACI, Fortunato. Prólogo. In: ESQUIVEL, J; GARCIA, F; HADIDA, M; HOUDIN, V. Creencias y religiones en el Gran Buenos Aires. El caso de Quilmes. Quilmes: Universidad Nacional de Quilmes, 2001. p. 13-31.

ORO, Ari Pedro. Considerações sobre a modernidade religiosa. Sociedad y religión, n. 14/15, p.61-67, nov. 1996.

PODSELVER, Lourence. La techouva. Nouvelle orthodoxie juive et conversion interne. Annales Histoire, Sciences sociales, Paris, ano 57, n. 2, p.275-296, marçoabril. 2002.

La tradition réinventée: Les hassidim de Loubavitch en France. Revue des études juives, Belgique, n. 3-4, p.441-450, jul-déc. 1992.

PRANDI, Reginaldo. Religião, biografia e conversão: escolhas religiosas e mudanças da religião. Tempo e presença, Rio de Janeiro, ano 22, n. 310, p.34-44, mar-abr. 2000.

SCHENKOLEWSKY-KROLL, Silvia. Continuidad y cambio en las corrientes políticas del judaísmo del centro y este de Europa en su transición a América Latina. El caso de Argentina, siglo XX. In: MALLINOWSKY, M; MIODUNKA, W. (Eds.). Comunidades de ascendencia centro-oriental europea en América Latina al advenimiento del siglo XXI. Sus roles y funciones locales e interculturales. Warszawa: Centro de Estudios Latinoamericanos Universidad de Varsovia, 2001. p. 61-71.

SETTON, Damián. Instituciones e identidades en los judaismos contemporáneos. 2006. Dissertação (mestrado) Facultad de Ciencias Sociales, Universidad de Buenos Aires, Buenos Aires, 2006.

. Instituciones e identidades en los judaísmos contemporáneos. Informe de investigación, Buenos Aires, n.21, p.1-118, feb. 2009.

. Jabad Lubavitch. In: FORNI, F; MALLIMACI, F; CARDENAS, L. (Coords.). Guia de la diversidad religiosa de Buenos Aires, tomo 2. Buenos Aires: Biblos, 2008. p. 201-206.

Las redes de educación judaica no formal y la participación de los jóvenes. In: NUEVAS VOCES PARA UNA NUEVA TRIBU. PRIMER ENCUENTRO DE JOVENES INTELECTUALES AMIA., 2006, Buenos Aires. Anais... Buenos Aires: Milá, 2009. p. 59-63.

SORJ, Bernardo. Identidade judaica, diversidades e unidade. Disponível em: http://www.bernardosorj.com/ pdf/identidade_judaica_diversidade_e_unidade.pdf. Acesso: 18 mar. 2009.

STRUSBERG, Mariela; ÁLVAREZ, Horacio. Jabad Lubavitch. In: FORNI, F; MALLIMACI, F; CARDENAS, L. (Coords.). Guia de la diversidad religiosa de Buenos Aires. Buenos Aires: Biblos, 2003. p. 84-88.

TOPEL, Marta. As leis dietéticas judaicas: um prato cheio para a antropologia. Horizontes antropológicos, Porto Alegre, ano 9, n. 19, p.203-222, jul. 2003. - Jerusalém \& São Paulo: A nova ortodoxia judaica em cena. Rio de Janeiro: Top Books, 2005.

\section{autor Damián Setton}

Docente de la Facultad de Ciencias Sociales/UBA

Magíster en Ciencias Sociales/UBA

Recebido em 23/03/2009

Aceito para publicação em 06/11/2009 